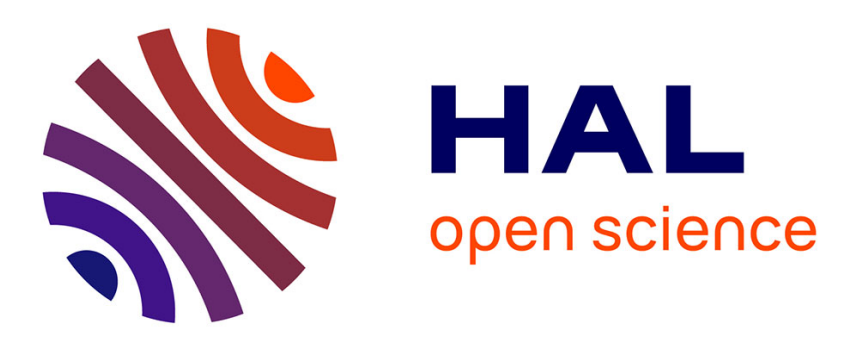

\title{
Prospect theory in the health domain: A quantitative assessment
}

\author{
Arthur E. Attema, Werner B.F. Brouwer, Olivier L'haridon
}

\section{To cite this version:}

Arthur E. Attema, Werner B.F. Brouwer, Olivier L'haridon. Prospect theory in the health domain: A quantitative assessment. Journal of Health Economics, 2013, 32 (6), pp.1057-1065. 10.1016/j.jhealeco.2013.08.006 . halshs-00866788

\section{HAL Id: halshs-00866788 \\ https://shs.hal.science/halshs-00866788}

Submitted on 14 Oct 2013

HAL is a multi-disciplinary open access archive for the deposit and dissemination of scientific research documents, whether they are published or not. The documents may come from teaching and research institutions in France or abroad, or from public or private research centers.
L'archive ouverte pluridisciplinaire HAL, est destinée au dépôt et à la diffusion de documents scientifiques de niveau recherche, publiés ou non, émanant des établissements d'enseignement et de recherche français ou étrangers, des laboratoires publics ou privés. 


\title{
Prospect theory in the health domain: A quantitative assessment $^{1}$
}

\author{
Arthur E. Attema ${ }^{\mathrm{a}}$, Werner B.F. Brouwer ${ }^{\mathrm{b}}$ and Olivier l'Haridon ${ }^{\mathrm{c}}$
}

${ }^{a}$ (Corresponding author) iBMG/iMTA, Erasmus University, P.O. Box 1738, 3000 DR

Rotterdam, the Netherlands. E-mail: attema@bmg.eur.nl, --31-10.408.91.29 (O); --31-

10.408.90.81 (F)

b iBMG/iMTA, Erasmus University, P.O. Box 1738, 3000 DR Rotterdam, the Netherlands.

E-mail: brouwer@bmg.eur.nl

${ }^{\mathrm{c}}$ Crem-University Rennes 1 and Greghec, HEC Paris.

August, 2013

\footnotetext{
${ }^{1}$ We are grateful to Laurens Niëns and Matthijs Versteegh for advice on the experimental design. Mohammed Abdellaoui, Aurélien Baillon, Han Bleichrodt and Peter Wakker gave helpful comments on a previous version of this manuscript. The usual disclaimer applies.
} 


\section{ABSTRACT}

It is well-known that expected utility (EU) has empirical deficiencies. Cumulative prospect theory (CPT) has developed as an alternative with more descriptive validity. However, CPT's full function had not yet been quantified in the health domain. This paper is therefore the first to simultaneously measure utility of life duration, probability weighting, and loss aversion in this domain.

We observe loss aversion and risk aversion for gains and losses, which for gains can be explained by probabilistic pessimism. Utility for gains is almost linear. For losses, we find less weighting of probability $1 / 2$ and concave utility. This contrasts with the common finding of convex utility for monetary losses. However, CPT was proposed to explain choices among lotteries involving monetary outcomes. Life years are arguably very different from monetary outcomes and need not generate convex utility for losses. Moreover, utility of life duration reflects discounting, causing concave utility.

Key Words: Loss aversion, Cumulative prospect theory, QALY model, Utility of life duration 


\section{Introduction}

Health economic evaluations are increasingly used by policy makers to help allocate scarce health care resources. These evaluations often entail cost-utility analyses, where health benefits are expressed in terms of utility. The common utility model used is the Quality-Adjusted Life-Years (QALY) model (Pliskin et al., 1980), which is based upon expected utility (EU) theory. However, many descriptive violations of EU have been reported during the last decades (Starmer, 2000), including in the field of health economics (Bleichrodt et al., 2007; Llewellyn-Thomas et al., 1982; Treadwell and Lenert, 1999). This puts into question the empirical validity of the QALY model in its present form.

Cumulative Prospect theory (CPT, Tversky and Kahneman, 1992) has developed as an important alternative, with more descriptive validity. CPT's main deviations from EU are its reliance on a reference point (RP), a nonlinear transformation of probabilities into decision weights (probability weighting), and a higher sensitivity to losses than to gains as seen from this RP (loss aversion). Much research has been done to measure utility and/or probability weighting under CPT, both for monetary outcomes (Abdellaoui, 2000; Fehr-Duda et al., 2006; Tversky and Kahneman, 1992; van de Kuilen and Wakker, 2011; Wu and Gonzalez, 1999) and for health outcomes (Bleichrodt and Pinto, 2000; Miyamoto and Eraker, 1989; Verhoef et al., 1994), but quantifications of loss aversion have been less widespread. Only recently, a number of studies have proposed and implemented methods to measure indices of loss aversion for monetary outcomes (Abdellaoui et al., 2007, 2008, 2011b; Booij and van de Kuilen, 2009). However, so far loss aversion has not been quantified in the health domain. Bleichrodt and Pinto (2002) quantitatively investigated loss aversion in health applications, but their study did not estimate the parameters of CPT, and, hence, thus far no estimates of loss aversion in CPT are available.

This lack of investigations is worrying since the assumption of CPT renders various common utility elicitation methods invalid (Abdellaoui et al., 2008). Examples include the certainty equivalence (CE) method, the standard gamble (SG), and the time tradeoff (TTO) method, which do not account for loss aversion and/or probability weighting (Bleichrodt, 2002). These methods are all very relevant for health economic evaluations. Hence, methods that elicit the entire function of CPT in the health domain are pivotal, both to obtain unbiased estimates of utility of life duration curvature and to apply these estimates to correct health state assessment methods, such as the SG and TTO, for loss aversion, utility curvature, and probability weighting. For example, Bleichrodt (2002) showed that loss aversion exerts an upward bias on health state utilities elicited by SG and TTO, whereas utility curvature causes a downward bias on TTO utilities, and underweighting of high probabilities often results in SG utilities that are too high. Hence, correcting utility estimates is important in order 
to reduce the biases present in health state valuation techniques (Abellán-Perpinán et al., 2009a; Attema and Brouwer, 2009; Oliver, 2003; Wakker and Stiggelbout, 1995). This research is the first to perform such an elicitation, using life duration as an outcome. It involves measuring the utility of life duration, the decision weight of probability $1 / 2$, and loss aversion. For this purpose, we use the semiparametric method proposed by Abdellaoui et al. (2008) to measure CPT's parameters for money. However, when applying this method to life duration, a number of problems arise.

First, health outcomes necessarily involve a time dimension, since health states have a duration inextricably bound to them (Bleichrodt and Johannesson, 2001), whereas monetary outcomes can be transferred at a single point in time. Life duration consists of years in the future, with all years occurring at different times and, therefore, the utility function for life years is distorted by time preferences (Gafni and Torrance, 1984). All future life years are discounted, both those considered gains and those considered losses, which is equivalent to a concave utility of life duration function (Attema et al., 2012). This discounting is interspersed with common utility properties that are also present for monetary outcomes. As a result, the comparison between CPT for money and CPT for health is complicated. For example, the utility function for monetary losses is often assumed or found to be convex (Abdellaoui et al., 2007; Kahneman and Tversky, 1979; Tversky and Kahneman, 1992), because people tend to be risk seeking for small losses. On the other hand, as shown by Chateauneuf and Cohen (1994), risk seeking behavior in the loss domain can also co-exist with a concave utility function under CPT, which was indeed found by Abdellaoui et al. (2008). They attributed this to an overweighting of the probability of bad outcomes. The concavity caused by discounting of future life years implies a further countertendency to convexity resulting from this risk seeking behavior. Therefore, individuals may be risk seeking for losses in the health domain, but this can be balanced by overweighting probabilities of bad outcomes, as well as discounting of future life years, causing the shape of the utility function for losses to be ambiguous.

A second problem arising in the health domain is the determination of the location of the RP. Laboratory experiments often use small monetary outcomes as their stimuli. A natural RP then is the status quo, i.e., just 0 , and any money won in the experiment is considered a gain, whereas any money that has to be paid to the experimenter will be considered a loss (although the latter is done only occasionally for real outcomes). It is, however, not so clear where the RP lies for the type of health outcomes that are considered in this study. One could argue that the RP is the expected remaining lifetime (e.g., using a mortality table or subjective life expectancy), the lowest outcome (Attema et al., 2012; Bleichrodt et al., 2001), the sure outcome (van Osch et al., 2004; van Osch and Stiggelbout, 2008) or the highest outcome in a choice situation, or that it depends on the goals of the respondents (van Osch et al., 2006). It is also likely to depend on the decision context and the framing of the questions. Hence, the RP is likely to be more heterogeneous among individuals in the health domain than in the monetary domain. 
It is possible to attempt to estimate the reference point separately for each individual by eliciting the point of inflection of the utility function, i.e., the point where the function switches from convex to concave (Schmidt and Zank, 2012). Such an approach was performed by Verhoef et al. (1994) for life duration. However, they did not formally test where the function was convex and where it was concave, but instead assumed it took a logistic shape and estimated this on their CE data. Using the obtained coefficients, one can then solve for the inflection point. Alternatively, one can directly elicit individual reference points by asking people what the number of remaining life years is such that when they life shorter they will consider this a loss, and when they live longer, they consider all years beyond that number a gain (Miyamoto and Eraker, 1989). However, this kind of question is not easy to answer. One possibility would be to ask respondents for their expected age of death (van Nooten and Brouwer, 2004). A hypothetical scenario where they will live longer [shorter] than until this age may then be considered a gain [loss].

The location of the RP is essential in estimating the utility functions for gains and losses and loss aversion, and, hence, the determination of this location is crucial. Instead of assuming that RP is one of the outcomes mentioned in the previous paragraph, or trying to elicit it individually, we attempted to induce the RP by explicitly describing it. This RP was subsequently used to measure CPT's functional form. Previous research indicates that such a description indeed causes respondents to consider this location as their RP (Robinson et al., 2001). Furthermore, a change in sign of the second derivative of the utility function (e.g., from positive [convex] to negative [concave]) may be a genuine property for the utility for gains/losses and, therefore, does not necessarily have to indicate the reference point.

Our results indicate that individuals are risk averse for both gains and losses. We find a concave utility function for losses and a close to linear utility function for gains under CPT. Finally, individuals are loss averse, with an estimated loss aversion smaller than those found for monetary outcomes.

This paper is organized as follows. Section 2 introduces notation and describes the experimental method. Section 3 provides details of the experiment and Section 4 continues with a presentation of the results. Finally, Section 5 discusses the results and Section 6 concludes.

\section{Method}

We let $(\mathrm{p}, \mathrm{x} ; \mathrm{y})$ denote a binary prospect that gives outcome $\mathrm{x}$ with probability $\mathrm{p}$ and outcome $\mathrm{y}$ with probability 1-p, with outcomes being real numbers (i.e., life years in the experiment described in 
Section 3$)^{2}$. A decision maker's preference relation $\geqslant$ is assumed to be a weak order, i.e., it is transitive (if $x \geqslant y$ and $y \geqslant z$, then $x \geqslant z$ ) and complete (either $x \geqslant y$, or $y \geqslant x$, or both). The relation $\succ$ denotes the asymmetric part of $\succcurlyeq$, and $\sim$ denotes indifference. Throughout this paper, we use the notation ( $\mathrm{p}, \mathrm{x} ; \mathrm{y})$ if $\mathrm{x} \geq \mathrm{y} \geq 0[\mathrm{x} \leq \mathrm{y} \leq 0, \mathrm{x}>0>\mathrm{y}]$ for gain [loss, mixed] prospects.

EU evaluates preferences over two-outcome prospects by:

$E U(p, x ; y)=p \times u(x)+(1-p) \times u(y)$.

However, because of the aforementioned empirical deficiencies of EU, more general specifications that incorporate CPT and rank-dependent utility (RDU) have been developed, also in the health domain (Bleichrodt and Miyamoto, 2003; Bleichrodt and Pinto, 2005; Bleichrodt and Quiggin, 1997). According to CPT, which is a generalization of RDU, the evaluation of prospects becomes (Wakker, $2010)^{3}$ :

$$
C P T(p, x ; y)=w^{+}(p) \times(u(x)-u(y))+u(y)
$$

for gain prospects;

$$
C P T(p, x ; y)=w^{-}(p) \times(u(x)-u(y))+u(y)
$$

for loss prospects, and;

$$
C P T(p, x ; y)=w^{+}(p) \times u(x)+w^{-}(1-p) \times u(y)
$$

for mixed prospects.

An example using one of the questions asked in the experiment may clarify this notation. Let us consider $\mathrm{j}=3$ from Table 1 (as explained in Section 3.3). There we have $\mathrm{x}=15$ and $\mathrm{y}=10$ in the gain prospect and $\mathrm{x}=-15$ and $\mathrm{y}=-10$ in the loss prospect. Furthermore, these prospects involved $\mathrm{p}=1 / 2$. According to EU the gain prospect will be evaluated by (and likewise for the loss prospect):

$E U\left(\frac{1}{2}, 15 ; 10\right)=1 / 2 \times u(15)+1 / 2 \times u(10)$.

According to CPT, the gain prospect will be evaluated by:

\footnotetext{
${ }^{2}$ Our experiment only uses binary prospects and, hence, we do not consider prospects with more than two outcomes here.

${ }^{3}$ Note that CPT (Tversky and Kahneman, 1992) and original PT (Kahneman and Tversky, 1979) coincide for binary prospects.
} 
$C P T\left(\frac{1}{2}, 15 ; 10\right)=w^{+}\left(\frac{1}{2}\right) \times(u(15)-u(10))+u(10)$.

The losses will be evaluated by:

$\operatorname{CPT}\left(\frac{1}{2},-15 ;-10\right)=w^{-}\left(\frac{1}{2}\right) \times(u(-15)-u(-10))+u(-10)$.

Finally, suppose we have $x=5$ and $y=-2$ in a mixed prospect. This is evaluated by:

$\operatorname{CPT}\left(\frac{1}{2}, 5 ;-2\right)=w^{+}\left(\frac{1}{2}\right) \times u(5)+w^{-}\left(\frac{1}{2}\right) \times u(-2)$.

Several studies have proposed methods for measuring the entire CPT function in a monetary context. Abdellaoui et al. (2007) and Booij and van de Kuilen (2009) proposed nonparametric approaches to measure utility, probability weighting ${ }^{4}$ and loss aversion under CPT for monetary outcomes, making use of gambles, whereas Tversky and Kahneman (1992) and Booij et al. (2010) used a parametric approach. Instead, Abdellaoui et al. (2008) proposed a semi-parametric approach, which was subsequently applied by Abdellaoui et al. (2011b).

The CPT function will be measured using an adaptation of the method of Abdellaoui et al. (2008). This semi-parametric method uses certainty equivalences (CEs) to elicit the parameter(s) of a predetermined parametric utility function. It needs substantially fewer questions and, hence, is significantly less time consuming than nonparametric methods (Fox and Poldrack, 2008). Furthermore, the different CEs are not susceptible to error propagation, because they are not linked. On the other hand, the advantage of this method over a fully parametric method is that it needs not make parametric assumptions about probability weighting and, hence, these measurements are not confounded by assumptions about the shape of this function (Abdellaoui et al., 2008).

The semi-parametric method entails three stages. First, the utility function for gains and the decision weight of one probability are simultaneously elicited. This is achieved by eliciting CEs of a number of two-outcome prospects. The outcomes of the prospect are changed in this process, whereas the probability of obtaining each outcome is the same for all prospects. By assuming CPT and a particular parametric shape of the utility function, one can then estimate the parameter(s) and decision weight of the fixed probability that best fit the elicited data. Second, the same is done in the loss domain. Finally, the value functions for gains and losses are linked by selecting a gain amount within the range of values measured in the first step and then, using a mixed prospect, determining the

\footnotetext{
${ }^{4}$ Only Abdellaoui et al. (2007) estimated probability weighting. Booij and van de Kuilen (2009) solely estimated utility curvature and loss aversion, and made several assumptions about probability weighting.
} 
maximum loss amount such that a subject still prefers the mixed prospect. This allows for estimating the loss aversion index, $\lambda$, which governs the exchange rate between gain and loss utility units, allowing a comparison between utilities of gains and utilities of losses (Köbberling and Wakker, 2005). In particular, we follow Köbberling and Wakker (2005) and Abdellaoui et al. (2008) in assuming that observable utility $\mathrm{U}$ is a composition of $\lambda$ and a basic utility $\mathrm{u}$, with:

$U(x)=\left\{\begin{array}{l}u(x) \text { if } x \geq 0 \\ \lambda u(x) \text { if } x<0\end{array}\right.$

According to this quantification, an individual is classified as loss averse, i.e. giving more weight to utility units in the loss domain than the same absolute utilities in the gain domain, if $\lambda>1$.

\subsection{Utility and decision weight elicitation}

The utility elicitation is similar to that of Abdellaoui et al. (2008, S.2.1) except that we consider the exponential family for utility of gains and losses. The advantage of the exponential family in our study is that it elicits utility independently of the RP. That is, the parameter estimates will be independent from the location of the $\mathrm{RP}^{5}$.

The exponential family (characterized by constant absolute risk aversion) was defined by $\mathrm{u}(\mathrm{x})=[1-$ $\exp (-\gamma \mathrm{x})] / \gamma$ for gains and $\mathrm{u}(\mathrm{x})=[\exp (\delta \mathrm{x})-1] / \delta$ for losses, with $\gamma, \delta \neq 0$. For $\gamma, \delta=0$, it was defined by $u(x)=x$. For gains, the exponential function is concave if $\gamma>0$, convex if $\gamma<0$, and linear if $\gamma=0$. For losses, it is concave if $\delta<0$, convex if $\delta>0$ and linear if $\delta=0$.

For each prospect $\mathrm{i}$ in the gain (loss) domain, we elicit a $\mathrm{CE}_{\mathrm{i}}$ such that the respondent is indifferent between gaining (losing) $\mathrm{CE}_{\mathrm{i}}$ years for certain and the prospect that provides a $50 \%$ chance of gaining (losing) a higher amount $\mathrm{x}_{\mathrm{i}}$ and $50 \%$ chance of gaining (losing) a lower amount $\mathrm{y}_{\mathrm{i}}$. If the respondent's preferences can be represented by CPT and the exponential utility function, this indifference can be evaluated in the gain domain by the following equation:

$\frac{1-\exp \left(-\gamma C E_{i}\right)}{\gamma}=\omega^{+} \times\left(\frac{1-\exp \left(-\gamma x_{i}\right)}{\gamma}-\frac{1-\exp \left(-\gamma y_{i}\right)}{\gamma}\right)+\frac{1-\exp \left(-\gamma y_{i}\right)}{\gamma}$

\footnotetext{
${ }^{5}$ This follows from the mathematical properties of this model: it implies that future life years are discounted at a constant rate; hence, the distance from an outcome to the reference point does not matter, as the per-period discount rate is the same for all periods. The only change, therefore, is that the value of $\gamma$ has to be rescaled, whereas the decision weight and goodness of fit do not change.
} 
where $\omega^{+}=\mathrm{w}^{+}(1 / 2)$. Solving this expression for $\mathrm{CE}_{\mathrm{i}}$ gives us a regression equation that enables the simultaneous estimation of the utility function parameter $\gamma$ and the decision weight $\omega^{+}$through nonlinear least squares:

$C E_{i}=-\frac{\ln \left(\omega^{+}\left(\exp \left(-\gamma x_{i}\right)-\exp \left(-\gamma y_{i}\right)\right)+\exp \left(-\gamma y_{i}\right)\right)}{\gamma}$

The procedure for estimating utility and decision weight is similar in the loss domain, giving the following regression equation that enables the simultaneous estimation of the utility function parameter $\delta$ and the decision weight $\omega^{-}$through nonlinear least squares:

$C E_{i}=\frac{\ln \left(\omega^{-}\left(\exp \left(\delta x_{i}\right)-\exp \left(\delta y_{i}\right)\right)+\exp \left(\delta y_{i}\right)\right)}{\delta}$

\subsection{Loss aversion elicitation}

The loss aversion index $\lambda$ could be simultaneously estimated by selecting two of the elicited $\mathrm{CE}_{\mathrm{i}} \mathrm{s}$ for gains, $\mathrm{G}^{*}$, and determining the loss $\mathrm{L}^{*}$ for which the subject was indifferent between a prospect giving a $50 \%$ chance of gaining $\mathrm{G}^{*}$ and a $50 \%$ chance of losing $\mathrm{L}^{*}$, and the status quo: $\left(\mathrm{p}_{\mathrm{g}}, \mathrm{G}^{*} ; \mathrm{L}^{*}\right) \sim 0$ (i.e., a mixed prospect). This gives:

$\omega^{+} \mathrm{u}\left(\mathrm{G}^{*}\right)+\omega^{-} \lambda \mathrm{u}\left(\mathrm{L}^{*}\right)=0$

In terms of the exponential utility function, this translates into:

$\omega^{+} \times\left(\frac{1-\exp \left(-\gamma G^{*}\right)}{\gamma}\right)+\omega^{-} \times \lambda \times\left(\frac{\exp \left(\delta L^{*}\right)-1}{\delta}\right)=0$

The mixed prospect, when solving for $\mathrm{L}^{*}$, results in the following regression equation:

$L^{*}=\frac{\ln \left(1-\left(\omega^{+} \times\left(1-\exp \left(-\gamma G^{*}\right)\right) / \omega^{-} \lambda\right) \times(\delta / \gamma)\right)}{\delta}$

\section{Experiment}




\subsection{Subjects}

The subjects were 80 undergraduate students in business administration at Erasmus University Rotterdam. They received course credits for their participation.

\subsection{Procedure}

The experiment was run on computers, in sessions with 4 respondents and 1 experimenter. The subjects were separated by partitions and did not communicate with each other. They could consult the experimenter in case of questions. It was made clear to them that there were no right or wrong answers. Each task of the experiment started with instructions on the computer screen and two practice questions. Printed instructions were also handed out, so that subjects could always verify something, or read these instead of the electronic instructions if they did not like to read them from the screen. The experiment lasted 30 minutes on average, including reading the instructions and performing the practice questions. A translation of the instructions can be found in Appendix 1.

The indifferences were elicited by means of a series of binary choices, because previous research has found that inferring indifferences from a set of choices results in fewer inconsistencies than when asking subjects directly for their indifference values (Bostic et al., 1990). A subject could return to a previous question if (s)he made a mistake.

A subject had to choose one of two prospects in the CE task, where the left option was always riskless. We included a consistency test by repeating the second or third iteration for some randomly selected questions at the end of an iteration sequence. For the mixed prospects, we repeated the third iteration at the end of one iteration sequence.

\subsection{Stimuli}

The utility functions for both gains and losses were elicited by the use of $7 \mathrm{CE}$ questions each. It was made clear to the subjects that they should imagine living 30 more years in full health, after which they would die. Hence, we induced an RP of living 30 more years.

In the gain part, the subjects then had to determine which of two drugs, each of which could increase their life beyond 30 years, they would choose if they were in this situation. The riskless prospect contained a drug that would increase lifetime with $\mathrm{CE}_{\mathrm{i}}$ years for certain, whereas the risky option involved a drug that would have $50 \%$ chance of gaining $\mathrm{x}$ years and a $50 \%$ chance of gaining $\mathrm{y}$ years, with $0 \leq \mathrm{y}<\mathrm{CE}_{\mathrm{i}}<\mathrm{x}$. All life extensions were spent in full health.

In the loss part subjects were instructed to imagine that they had no other option than to take a drug because of a disease that would decrease their remaining lifetime (or at best remain the same). 
Now, the riskless prospect contained a drug that would decrease lifetime with $\mathrm{CE}_{\mathrm{i}}$ years for certain, whereas the risky option involved a drug that would have 50\% chance of losing $\mathrm{x}$ years and a 50\% chance of losing y years, with $0 \geq y>\mathrm{CE}_{\mathrm{i}}>\mathrm{x}$.

The stimuli of the prospects of these questions are shown in Table 1. The amounts of gains and losses ranged between 0 and 20 years. Because remaining lifetime obviously cannot become negative, the maximum possible loss amount was 30 . Moreover, since the possibility of immediate death has been shown to create distortions in previous studies (Bleichrodt et al., 2003; Tversky and Kahneman, 1986), it was preferable to have a maximum loss amount smaller than 30 years; hence we chose a maximum loss of 20 years.

\section{<TABLE 1 HERE >}

We used only one probability $(\mathrm{p}=1 / 2)$, since Abdellaoui et al. (2008) found no significant differences between utilities obtained for $\mathrm{p}=1 / 2$ and $\mathrm{p}=1 / 3$, allowing a substantial reduction of cognitive burden. The order of the elicitation of the CEs was random. The order of the gain and loss parts was also randomized, although these parts were not interspersed. The latter would require more cognitive effort from the subjects, because they would then repeatedly have to change perspective from gains to losses, and vice versa, which would likely threaten data reliability.

Two elicitations were included to allow for estimation of the loss aversion index. Abdellaoui et al. (2008) used six estimations for this purpose, but found no significant differences between them, suggesting that one elicitation is sufficient to obtain reliable estimates. However, because in this study we used another domain and loss aversion indexes tend to be variable (Abdellaoui et al., 2007; Abdellaoui et al., 2008; Bleichrodt et al., 2001; Booij and van de Kuilen, 2009; Schmidt and Traub, 2002; Tversky and Kahneman, 1992), two elicitations were included to account for robustness. We

determined $\mathrm{L}^{*}$ such that $\left(1 / 2, G_{j}^{*} ; L_{j}^{*}\right) \sim 0$, for $\mathrm{j}=2,4$, where $\mathrm{j}$ stands for the number of the prospect in Table 1. That is, the subject could choose between maintaining the RP, or taking a gamble with $50 \%$ chance of gaining $\mathrm{G}^{*}$ years and $50 \%$ chance of losing $\mathrm{L}$ years, where $\mathrm{L}$ was varied until the subject was about indifferent at $\mathrm{L}^{*}$. The order of $\mathrm{j}$ was random.

\subsection{Analysis}

A subject was classified as risk averse [risk seeking] if at least 5 out of $7 \mathrm{CE}$ questions produced a risk averse [seeking] answer (i.e., a CE lower [higher] than the expected value of the prospect) ${ }^{6}$. This

\footnotetext{
${ }^{6}$ To allow for response error in elicited CE, we defined risk neutrality with a $+/-5 \%$ error margin around the expected value. Weakly risk averse or weakly risk seeking responses might therefore be classified as risk neutral
} 
allowed taking into account response error. Because the data were not normally distributed, we performed nonparametric statistical tests (Wilcoxon signed ranks tests for within-subjects analyses and Mann-Whitney tests for between-subjects analyses). Two-tailed p-values are reported.

\section{Results}

\subsection{Reliability}

Seven subjects were excluded because they did not understand (one of) the tasks. The replication of the second iteration led to the same choice as the initial question in $96.6 \%$ [85.6\%] of the cases for gains [losses], indicating a good reliability. The replication of the third iteration led to the same choice in $88.3 \%$ [86.3\%, 90.4\%] of the cases for gains [losses, mixed prospects]. A lower reliability for the third iteration than for the second iteration was to be expected, since the stimulus value was likely to be closer to the CE there. For losses, however, the reliabilities were similar for the second and third iteration. These reliabilities are comparable to those of earlier studies (Abdellaoui et al., 2008; Stott, 2006).

For some CE questions, the order of the gain and loss parts turned out to have a (marginally) significant effect. In particular, subjects who answered the gain questions first had lower median CEs for all 7 questions in the gain part than those who started with the loss questions, of which 3 were (marginally) significant $\left(\mathrm{CE}_{1}, \mathrm{CE}_{3}\right.$, and $\mathrm{CE}_{7}: \mathrm{p}=0.055, \mathrm{p}<0.01$, and $\mathrm{p}=0.025$, respectively). This implies that the former group was more risk averse in the gain part. An explanation for this order effect may be that subjects who started with the loss questions were more inclined to 'gamble' in the gain questions, because then all outcomes were 'indeed positive', i.e., all outcomes were at least better than the loss outcomes they faced before. Such a distinction was not found in the loss part, where neither systematic nor significant differences were found between the two groups (for 5 CEs, the medians were equal, whilst it was higher [lower] for the group starting with loss questions for $\mathrm{CE}_{4}$ $\left[\mathrm{CE}_{5}\right]$, all p's>0.10). The observation of higher risk aversion for gains for subjects starting with the gain part highlights the importance of randomizing the order of the gain and loss parts; our data signal the presence of significant order effects ${ }^{7}$.

\subsection{CEs and risk attitude}

responses. As a consequence, our classification result can be interpreted as a conservative estimate of the amount of risk aversion or risk seeking.

${ }^{7}$ Pinto-Prades et al. (2009) also found significant order effects in the case of willingness to pay (WTP) for health improvements, where WTP was lower if they started with the lowest health gain. 
The median answers to the CE questions, as well as their interquartile ranges, are shown in Table 2. This table shows a clear tendency of risk aversion, both for gains and for losses. Overall, 54.8\% [38.2\%, 7.0\%] of the responses were consistent with risk aversion [risk neutrality, risk seeking] for gains, whilst for losses these percentages were $51.9 \%, 41.7 \%$, and $6.4 \%$, respectively. Comparing each CE for gains with its counterpart for losses, we found 36.8\% [26.4\%] to reflect risk aversion [risk neutrality] for both. Furthermore, 10.6\% [14.3\%] of the CEs was risk neutral [averse] for gains and risk averse [neutral] for losses.

\section{$<$ TABLE 2 HERE>}

The classification of subjects in terms of risk attitude for gains and losses is presented in Table 3, and shows a similar picture as the one derived from the individual responses. No subject was classified as risk seeking, neither for gains nor for losses. The largest group consisted of subjects who were risk averse over the whole domain $(24.7 \%)$. The other classifications were also similar to the classification according to the stand alone answers to the separate questions, although there were somewhat more mixed subjects for losses than for gains. The proportion of risk averse subjects did not significantly differ from the proportion of risk neutral subjects, neither for gains nor for losses $(\mathrm{p}>0.22)$.

\section{$<$ TABLE 3 HERE>}

There was a high degree of risk aversion in the mixed prospects, especially for $\mathrm{j}=4$ (Table 1 ). The median size of the loss establishing indifference varied between 0.46 and 0.79 of the size of the corresponding median gain $\left(j=2: G^{*}=3.85, L^{*}=3.05 ; j=4: G^{*}=8.50, L^{*}=3.95\right)$. In total, $77.4 \%$ of the responses were risk averse. 48 subjects were risk averse in both mixed prospects, 8 were risk seeking, and 17 were classified as mixed. This degree of risk aversion was comparable to the degree of risk aversion in the gain prospects.

\subsection{Utility for gains and losses}

Table 4 shows the median parameters of the exponential model, based on the individual data. The median coefficient was significantly different from 0 for gains $(\gamma=0.25, \mathrm{p}=0.03)$ and losses $(\delta=-1.24$, $\mathrm{p}<0.01)$. The coefficients were significantly different between gains and losses $(\mathrm{p}<0.01)$. Figure 1 in Appendix 2 shows the distribution of individual utility parameters.

\section{$<$ TABLE 4 HERE $>$}


Table 5 gives subjects' classifications based on their estimated utility parameters. The most common pattern was concave utility for both gains and losses. It turns out that the risk aversion for gains was to a large degree due to probability underweighting; whereas, the utility function was indeed less concave than would be suggested when assuming EU.

\section{$<$ TABLE 5 HERE>}

\subsection{Loss aversion}

We found evidence for loss aversion $(\lambda=1.18)$. The median of the individual loss aversion indexes was significantly different from $1(\mathrm{p}=0.03)$. The interquartile range indicated a considerable amount of variation at the individual level, as is common in studies of loss aversion (Abdellaoui et al., 2008; 2011b). At the individual level, classifying individuals as loss averse if their median loss aversion index exceeded 1, 44 of the 73 subjects $(60.3 \%)$ met this criterion. This proportion was higher than the proportion of gain seeking subjects $(39.7 \%, \mathrm{p}<0.01)$. Figure 1 in Appendix 2 shows the distribution of individual loss aversion indexes.

\subsection{Probability weighting}

We found significant weighting of probability $1 / 2$, but only in the gain domain. There was pronounced underweighting of probability $1 / 2$ for gains (median $\omega^{+}=0.46, p=0.01$ ). For losses, the decision weight of probability $1 / 2$ did not significantly differ from $1 / 2$ (median $\omega^{-}=0.49, p=0.77$ ). The weight was significantly higher for losses than for gains $(\mathrm{p}=0.03)$. Consistent with previous evidence, decision weights for losses departed much less from linearity than those for gains (Abdellaoui, 2000; Booij et al., 2010).

\subsection{Expected utility}

We reran the analysis assuming EU. Under EU, linear weighting of probabilities is imposed and the decision maker treats all outcomes as gains. Since the latter assumption removes any differences between gain, loss and mixed prospects, we also performed this analysis using the pooled gain, loss and mixed data. As can already be inferred from the data presented in Table 1, the responses indicated a high degree of risk aversion for both gains and losses. Hence, the above analysis makes clear that underweighting of probability $1 / 2$ captures all of the risk aversion for gains. We would therefore expect concave utility functions, since risk attitude is entirely captured by utility curvature in EU. The results shown in Table 6 indeed confirm this prediction; the median utility function becomes concave 
$(\mathrm{p}<0.01)$. This illustrates that erroneously neglecting probability weighting leads to distorted estimations of utility.

\section{$<$ TABLE 6 HERE>}

\subsection{Analysis assuming $R P=0$}

One explanation for our finding of risk aversion for both gain and loss prospects is that subjects may indeed have treated all outcomes as gains (i.e., they may have taken their RP to be 0 life years). In order to test whether this could be a feasible explanation, we reanalyzed the data under this assumption, which corresponds to the RDU model initially proposed by Quiggin (1982). As in the EU case, this entailed considering the total life expectancies instead of the deviations from a life expectancy of 30 years. Since this assumption removed any differences between gain and loss prospects, we performed this analysis using the pooled gain and loss data. ${ }^{8}$

Table 6 presents the results of this analysis. Unsurprisingly, we found utility to be less curved than utility under EU $(\mathrm{p}<0.01)$. The difference between the results under CPT and under RDU lies in the fact that probability weighting captures a part of risk attitudes through probabilistic risk attitudes (i.e., underweighting or overweighting of probabilities). We found evidence for underweighting of probability $1 / 2$ (median $\omega=0.44, \mathrm{p}<0.01)$.

The nested nature of the three models allows for carrying out statistical tests to compare the various theories. CPT is a generalization of RDU, which is itself a generalization of EU. Then EU is nested within RDU, which is nested within CPT. Using this nested structure we performed likelihood ratio tests at the individual level to determine which model better accounted for the data. EU performed better than RDU for 16 out of the 73 subjects. Hence, it is worth using an RDU model rather than a simple EU model to account for attitude towards life years. When compared with CPT, we found RDU to better fit the data in only one case. Then, assuming $\mathrm{RP}=0$ did not bring any improvement in the analysis when compared to both the standard EU-QALY model and CPT. When compared to CPT, EU explained the data better for only one subject. ${ }^{9}$ Therefore, taking into account sign-dependence through CPT rather than assuming EU or RDU greatly increased the explanatory power of the model.

\footnotetext{
${ }^{8}$ Alternatively, the reference point may be the highest outcome, 50, implying all outcomes are treated as losses. However, given the irrelevance of the location of the RP in the exponential utility function, this would give the same results as when $\mathrm{RP}=0$.

${ }^{9}$ Standard measures of goodness of fit, like the Akaike Information Criterion and the Bayesian Information Criterion lead to similar results.
} 


\section{Discussion}

This paper provides the first quantitative estimation of an index of loss aversion in the health domain, in addition to estimates of utility of life duration and decision weights. Our study adds new evidence to the debate about transferability of utility between domains, which is ongoing (Abellán-Perpinán et al., 2009b; Wakker, 1994). We found significant loss aversion, with coefficients of lower magnitude than those reported in studies on loss aversion for monetary outcomes (Abdellaoui et al., 2007; 2008; Booij and van de Kuilen, 2009). Moreover, our finding of risk aversion over the entire domain of study is not in agreement with diminishing sensitivity as commonly observed in the monetary domain. In particular, our results suggest that a convex utility function for losses is not a universal phenomenon. Instead, the shape of this function may well depend on the outcome domain, as well as the magnitude of the stimuli.

\subsection{Loss aversion}

We observed more loss aversion in the mixed prospect with the higher gain than in the mixed prospect with the lower gain. The median answers to these questions suggest that respondents may have had a maximum number in their mind that they were prepared to risk losing. As a result, the loss aversion index is predicted to be positively correlated to the gain amount in the mixed prospect. This prediction is at odds with the usual assumption of constant loss aversion (Bleichrodt et al., 2001; Köbberling and Wakker, 2005; Tversky and Kahneman, 1991), and also rejects empirical evidence found for qualitative data in the health domain, which suggested that loss aversion decreases with life duration (Attema and Brouwer, 2012; Bleichrodt and Pinto, 2002; Bleichrodt et al., 2003). Therefore, more detailed research into the relationship between loss aversion and outcome magnitudes is called for.

\subsection{Utility}

Our results regarding risk aversion for gains are similar to those of previous studies (Abdellaoui, 2000; Abdellaoui et al., 2008). An interesting finding is that weighting of probability $1 / 2$ importantly explains this risk aversion, utility for gains being close to linear. Our results for losses also confirm those of Abdellaoui et al. (2008), who reported concave utility as well, although they did not observe risk aversion for losses as we do. The reason for this is that they find underweighting of the probability of the worst outcome for losses. Instead, we find slight overweighting of this probability ${ }^{10}$, which implies, as demonstrated in Section 4.6, that utility would be even more concave had we not accounted for probability weighting. It seems, therefore, that our subjects did not weight probabilities

\footnotetext{
${ }^{10}$ A similar result was observed by Booij et al. (2010).
} 
much in the loss domain, implying their risk aversion in this domain is indeed due to concave utility; whereas, they were pessimists with regard to probabilities in the gain domain, explaining much of their risk averse behavior there.

Nevertheless, most studies in this field found a concave utility function for gains (Stiggelbout et al., 1994), even when controlling for probability weighting (Bleichrodt and Pinto, 2005; Bleichrodt and Pinto, 2000; Wakker and Deneffe, 1996), or when using a riskless domain, not susceptible to probability weighting (Abellán-Perpinán et al., 2006; Attema et al., 2012). Verhoef et al. (1994) found that a logistic utility function provided a good fit to their data, claiming the transition from convex to concave utility occurred at an aspiration level that could be regarded as the reference point, and, hence, concluded the convexity occurred on the loss side and the concavity on the gains side. However, this conclusion could not be verified by other evidence.

We are aware of only one study that observed convex utility of life duration for gains (Knoph Kvamme et al., 2010). This study reported convex utility for small life extensions using a willingness to pay approach. However, a horizon of at most 1 year was used, whereas the other studies, as well as our study, used a much larger time horizon. Knoph Kvamme et al. (2010) attributed their finding to a threshold effect, but this is not likely for our gain amount of maximally 20 years. Furthermore, Attema et al. (2012) reported a concave utility of life duration function in a riskless environment, and also found concavity for results obtained with a CE method, even after correcting for the median probability weighting estimates obtained by Tversky and Kahneman (1992).

\subsection{Explanations}

Several explanations can be offered for our findings regarding the utility function for losses. First, it should be kept in mind that prospect theory was originally proposed to explain choices among lotteries involving monetary outcomes (Kahneman and Tversky, 1979), and empirical studies reporting convex utility for losses indeed typically used small amounts of such outcomes. Therefore, it is not at all clear that the use of life years should also generate convex utility for losses. If remaining life expectancy is very small, the situation may instead be comparable to that of being near 'ruin'. Researchers tend to agree that utility for losses gets concave near ruin for money (Kahneman and Tversky, 1979; Laughhunn et al., 1980; Libby and Fishburn, 1977; Marquis and Holmer, 1996; Ogaki and Zhang, 2001), so if loss of life duration is like 'ruin', it becomes more natural to observe concave utility.

An alternative explanation for the concave utility function may be that time preference generates enough concavity to more than offset the convexity due to diminishing sensitivity. There is reason to doubt this possibility, however, because if it were true, this would suggest more concavity for gains than for losses. Indeed, we find the opposite, and very little concavity for gains when adjusting for probability weighting. 
Third, our decision problem may be perceived as a situation of a delayed resolution of uncertainty (Abdellaoui et al., 2011a). That is, subjects may have considered the gain prospects as uncertain during the 30-year reference duration, and after that they would 'learn' the resolution of uncertainty (e.g., either no gain and, hence, death after those 30 years, or a gain and some additional years). The situation becomes radically different for loss prospects under this reasoning. For example, prospect $j=4$ could give either a loss of 20 years or no loss at all. If the bad outcome then occurs, the resolution of uncertainty will happen after 10 years already. Consequently, the risk aversion in the loss domain may be the result of the interaction between discounting, uncertainty, and the timing of resolution of uncertainty. A similar reasoning applies to mixed prospects, where the situation actually gets even more complicated, because there the subject's response determines what the timing of resolution of uncertainty will be. Hence, it becomes endogenous and subject-specific.

A fourth explanation is that subjects may have regarded zero remaining life years as their RP, and, hence, may not have considered any outcome as a loss. However, the findings of loss aversion and significant differences between the utility curvatures for gains and losses indicate that subjects are sensitive to framing of questions as either gains or losses, and do not treat all outcomes as gains, or, if they do, do not treat all gains similarly.

Finally, a possible explanation entails that people took the sure outcome as their RP. This would imply that they have considered all prospects, both in the gain part, the loss part, and the mixed part, as mixed. A problem that arises if this were indeed the case, however, is that the analysis becomes considerably more complicated. If respondents treat all prospects as mixed, each decision involves five different parameters (i.e., the utility curvature parameters and the decision weights for both gains and losses, and the loss aversion index). Furthermore, the RP is not exogenous anymore, but equals the CE which differs between subjects depending on their choices. As a result, a collinearity problem arises in the statistical analysis, making regression impossible. More research with a study design developed to explicitly deal with this issue is therefore warranted.

\subsection{Limitations}

The design of our study had several limitations. First, our assumption of exponential utility implies a constant discount rate, whilst empirical evidence suggests constant discounting does not always hold (Attema, 2012; Frederick et al., 2002). However, we also fitted the power utility function, which gave a similar goodness of $\mathrm{fit}^{11}$, and, as explained earlier, the exponential model provides several advantages over the power model. On the other hand, our results do not allow giving a conclusion regarding the relevance of the location of the reference point, which does not matter according to

\footnotetext{
${ }^{11}$ Results under the assumption of power utility are available upon request to the authors.
} 
exponential utility, but does according to power utility. Further research addressing this question is therefore needed.

Second, we could not separately estimate the utility function and the decision weight of probability $1 / 2$, but had to estimate them simultaneously. This may give estimates that are to some extent arbitrary. For example, the assumption of exponential utility produces lower estimates of the degree of underweighting of probability $1 / 2$ than the assumption of power utility.

Third, our sample consisted of a student population, and, hence, our findings cannot readily be extended to the general public. However, the use of such a convenience sample is common in this field (Abdellaoui et al., 2007, 2008; Oliver, 2003; Tversky and Kahneman, 1992), and existing empirical evidence suggests there are no systematic differences with more representative samples (Booij and van de Kuilen, 2009; Booij et al., 2010).

Finally, since we used only one single probability in our two-outcome prospects (i.e., 1/2), our study does not provide any evidence on the decision weights attached to other probabilities. In particular, we know that people heavily transform very small and large probabilities (Abdellaoui, 2000; Bleichrodt and Pinto, 2002; Gonzalez and $\mathrm{Wu}, 1999)$. This finding is especially relevant for the SG method, which is frequently used in health economics studies and often involves very small probabilities of extreme outcomes, such as immediate death (Oliver, 2003; van Osch et al., 2004). Hence, we recommend an extension of our study that implements different probabilities as a useful topic for future research.

\section{Conclusion}

We can conclude that results presented in this study suggest that the EU assumptions underlying the standard QALY model are not valid, justifying the use of non-EU QALY models. Furthermore, our results indicate that loss aversion plays a role also in decision making in the health domain, but it appears not to be constant. Finally, a concave utility function was observed for both gains and losses, rejecting the concept of diminishing sensitivity. The most notable finding of our study is the absence of risk seeking behavior in the loss domain. This highlights the need for more research to investigate whether this result was due to the health domain causing fundamentally different behavior than the monetary domain, or was caused by the specific methodology used here.

This first attempt to quantify the functional form of CPT in the health domain seems promising, but highlights that several hurdles still have to be taken. First, more investigation into the shape of the utility function is required to confirm the large decrease in concavity of the utility function for gains when accounting for probability weighting. Preferably, this should be done while separately measuring utility curvature and probability weighting, in order to better disentangle these two 
concepts. Second, more research is required to further investigate the precise influence of time preference; in particular regarding its ability to explain the observed risk averse behavior in the loss domain. Our findings of more concavity in the loss domain than in the gain domain suggest that time preference may not be the only phenomenon that should be considered. Third, the location of the RP in the health domain deserves further exploration. This location is less obvious for health outcomes than for monetary outcomes, and plays a crucial role in CPT. Finally, an extension of this study to a more representative sample of the general population would be worthwhile. 


\section{Tables}

Table 1. Stimuli of the gain and loss prospects

\begin{tabular}{|c|c|c|c|c|c|c|c|}
\hline & $\mathrm{j}=1$ & $\mathrm{j}=2$ & $\mathrm{j}=3$ & $\mathrm{j}=4$ & $\mathrm{j}=5$ & $\mathrm{j}=6$ & $\mathrm{j}=7$ \\
\hline$|x|$ & 5 & 10 & 15 & 20 & 20 & 20 & 20 \\
\hline$|y|$ & 0 & 0 & 10 & 0 & 5 & 10 & 15 \\
\hline
\end{tabular}

Table 2. Median CEs (interquartile ranges in parentheses)

\begin{tabular}{|l|l|l|}
\hline CE & Gains & Losses \\
\hline 1 & $2.25(1.90-2.25)$ & $2.75(2.75-3.25)$ \\
\hline 2 & $3.85(3.85-4.60)$ & $5.75(5.25-6.75)$ \\
\hline 3 & $12.25(11.90-12.25)$ & $12.75(12.75-13.75)$ \\
\hline 4 & $8.50(5.50-9.50)$ & $13(11.50-15.50)$ \\
\hline 5 & $10.50(8.50-11.50)$ & $13.50(12.50-15.50)$ \\
\hline 6 & $14.25(13.25-14.75)$ & $15.75(15.25-16.50)$ \\
\hline 7 & $17.25(16.63-17.75)$ & $17.75(17.75-18.10)$ \\
\hline
\end{tabular}

Table 3. Classification according to CEs

\begin{tabular}{|l|l|l|l|l|l|l|}
\hline & Losses & & & & & \\
\hline & & Risk averse & $\begin{array}{l}\text { Risk } \\
\text { neutral }\end{array}$ & $\begin{array}{l}\text { Risk } \\
\text { seeking }\end{array}$ & Mixed & Total \\
\hline Gains & Risk averse & 18 & 0 & 0 & 8 & 26 \\
\hline & $\begin{array}{l}\text { Risk } \\
\text { neutral }\end{array}$ & 0 & 5 & 0 & 2 & 7 \\
\hline & $\begin{array}{l}\text { Risk } \\
\text { seeking }\end{array}$ & 0 & 0 & 0 & 0 & 0 \\
\hline & Mixed & 9 & 12 & 0 & 19 & 40 \\
\hline & Total & 27 & 17 & 0 & 29 & 73 \\
\hline
\end{tabular}


Table 4. Estimation results, based on individual data

\begin{tabular}{|l|l|l|l|l|l|l|}
\hline \multicolumn{2}{|c|}{} & $\gamma$ & $\omega^{+}$ & $\delta$ & $\omega^{-}$ & $\lambda$ \\
\hline \multirow{2}{*}{} & Median & 0.25 & 0.46 & -1.24 & 0.49 & 1.18 \\
\cline { 2 - 7 } & IQR & $-0.49-1.91$ & $0.36-0.56$ & $-2.77--0.27$ & $0.43-0.59$ & $0.76-1.83$ \\
\hline
\end{tabular}

Table 5. Classifications according to utility functions

\begin{tabular}{|l|l|l|l|l|}
\hline \multicolumn{2}{|l|}{ Losses } & Concave & Convex & Total \\
\hline \multirow{3}{*}{ Gains } & Concave & 34 & 8 & 42 \\
\cline { 2 - 5 } & Convex & 23 & 8 & 30 \\
\cline { 2 - 5 } & Total & 56 & 16 & 73 \\
\hline
\end{tabular}

Table 6. Estimation results under EU and RDU

\begin{tabular}{|l|l|l|l|}
\hline & \multicolumn{1}{|c|}{ EU } & \multicolumn{2}{c|}{ RDU } \\
\hline & $\begin{array}{l}\text { Utility } \\
\text { parameter }\end{array}$ & $\begin{array}{l}\text { Utility } \\
\text { parameter }\end{array}$ & $\omega^{+}$ \\
\hline Median & 2.28 & 0.95 & 0.44 \\
\hline IQR & $1.20-3.70$ & $-0.68-3.51$ & $0.37-0.49$ \\
\hline
\end{tabular}




\section{Appendix 1: Instructions}

\section{GENERAL INSTRUCTIONS}

Welcome at this experiment on decision making regarding quality of life and life duration. We would like to emphasize that we are only interested in your preference, so there are no right or wrong answers!

The experiment consists of eight parts. Each part will be preceded by instructions about the task. These instructions will be appear on your screen, but you can also find them in the instruction set on your desk. To find out whether you have understood everything, we start each part with a couple of practice questions. Take your time to read and consider the questions carefully. You have enough time and there won't be a problem to finish the task within an hour. If you have any questions or remarks, don't hesitate to consult the leader of the experiment.

Good luck! 


\section{Gain Prospects}

Imagine you have 30 remaining years to live in full health. After that, you get a fatal disease, causing an immediate, painless death. However, recently, 2 drugs have been invented to do something about this. First, a drug (Drug A) is available that will extend your life 12 years, in full health. If you take this drug, this means that you have 42 remaining life years in full health, after which you still die of the aforementioned fatal disease. You have to take the drug only once and it has no side-effects. Second, a drug (Drug B) was invented that may extend your life 24 years in full health, meaning you would have 54 remaining life years in full health. However, it is not sure that this will happen. Drug B will be effective for half of the people, but not for the other half. There are no consequences for the people for whom Drug B is not effective. They will still live 30 more years in full health, as in the baseline situation. One cannot predict beforehand in whom Drug B strikes and in whom not. Striking or not depends solely on chance and, hence, has nothing to do with any personal features of the drug user. Therefore, the chance that this drug will be effective for you is, as for any other person, exactly $50 \%$. One can imagine here, for instance, that one tosses a fair coin, giving one 10 extra years if heads comes up, and 0 extra years if tails comes up. 50\% chance therefore means a chance of 1 out of 2 (or 50 out of 100). Drug B neither has any side-effect.

The question to you is to choose one of the two drugs, because you can only take one. When you have taken one, the other one won't have any effect anymore. If you take Drug A, you will live exactly 42 more years in full health for sure. If you take Drug B, you have a 50\% chance to gain 24 years and, thus, live 54 more years, but also a 50\% chance to gain nothing and live 30 more years in full health. Immediately after taking Drug B, the doctor can determine whether the drug is effective or not. Once this is known, one cannot change the situation. Assume no new drugs will be developed to change your situation.

In the following questions the scenario will be the same as in the instructions presented here, except for the number of remaining years to be lived. 


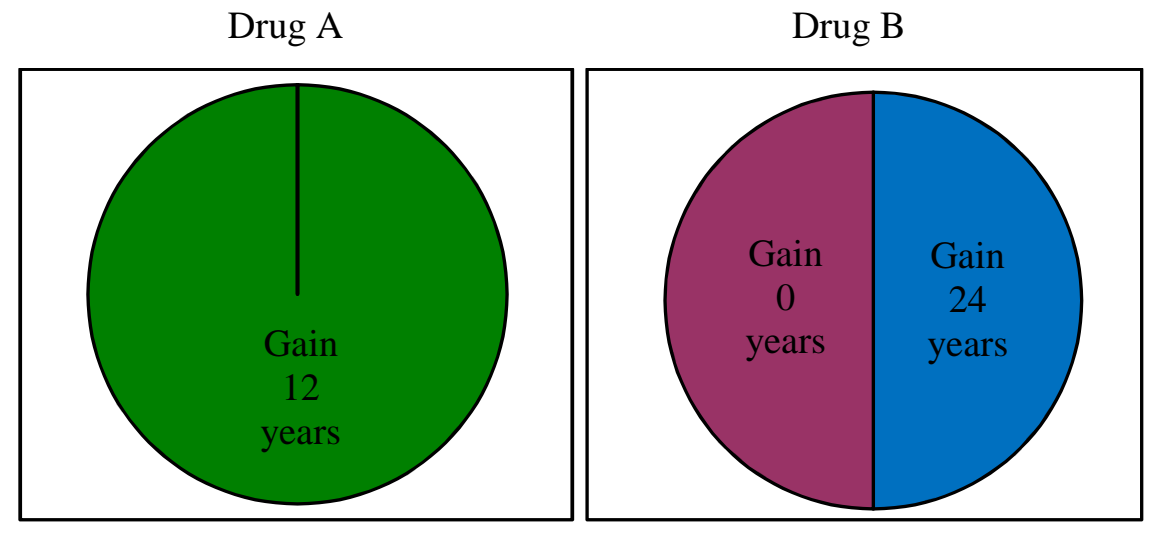




\section{Loss Prospects}

Imagine that initially you would have 30 remaining years to live in full health. After that, you would get a fatal disease, causing an immediate, painless death. Suddenly, however, you get another disease right now, forcing you to choose between 2 drugs. Both drugs cause you to stay fully healthy, but do shorten your remaining life duration (or have a chance to shorten it).

First, there is a drug (Drug A) available that shortens your life by 7 years. If you take this drug, you therefore have 23 remaining years of life in full health, after which you will die. You only have to take the drug once and it does not have any side-effects.

Second, there is a drug (Drug B) available that may shorten your life by 14 years, which would imply a remaining life time of 16 years in full health. It is, however, not certain that this will happen. For half of the people, drug B will shorten the life duration by 14 years, but not for the other half; the latter have the luck that Drug B does not shorten their remaining life duration. They will live 30 more years in full health, as in the baseline situation.

One cannot predict beforehand in whom Drug B shortens life duration. Shortening life duration or not depends solely on chance and, hence, has nothing to do with any personal features of the drug user. Therefore, the chance that Drug B will shorten you life duration, as for any other person, exactly 50\%. One can imagine here, for instance, that one tosses a fair coin, giving one 14 fewer years if heads comes up, and 0 fewer years if tails comes up. 50\% chance therefore means a chance of 1 out of 2 (or 50 out of 100). Drug B neither has any side-effect.

The question to you is to choose one of the two drugs, because you have to take one. If you take Drug A, you will live exactly 7 years shorter than in the initial situation, namely exactly 23 years in full health. If you take Drug B, you have a 50\% chance to die 14 years earlier, and, thus, live 16 more years in full health, but also a 50\% chance to lose nothing and live 30 more years in full health. Immediately after taking Drug B, the doctor can determine whether the drug is effective or not. Once this is known, one cannot change the situation. Assume no new drugs will be developed to change your situation.

In the following questions the scenario will be the same as in the instructions presented here, except for the number of remaining years to be lived. 

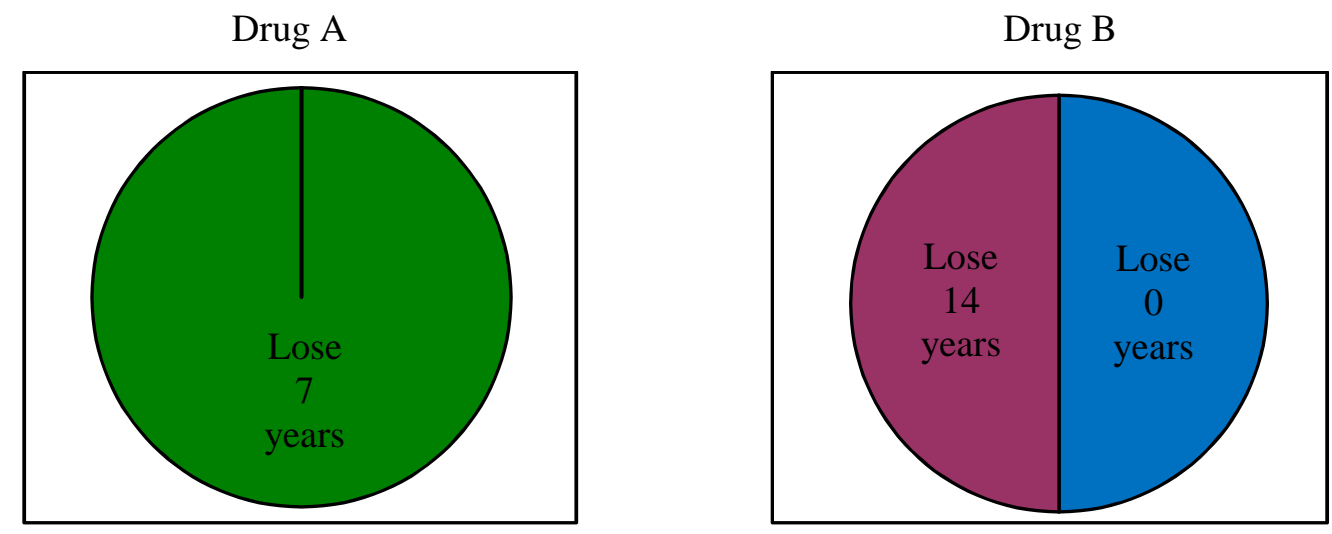


\section{Mixed Prospects}

Imagine you have 30 remaining years to live in full health. After that, you get a fatal disease, causing an immediate, painless death. However, recently, a drug has been invented to do something about this. This drug may extend your life by a specific number of years, in full health. If you take this drug, this means that you have more than 30 remaining life years in full health, after which you still die of the aforementioned fatal disease. You have to take the drug only once and it has no side-effects.

However, it is not sure that this will happen. The drug will be effective for half of the people, but not for the other half. The remaining life duration will be less than 30 years, in full health, for the people for whom Drug B does not strike. One cannot predict beforehand in whom the drug strikes and in whom not. Striking or not depends solely on chance and, hence, has nothing to do with any personal features of the drug user. Therefore, the chance that this drug will be effective for you is, as for any other person, exactly $50 \%$.

The question to you is whether you want to take the drug or not. In case you don't take the drug, you will live exactly 30 more years in full health for sure. If you do take the drug, you have a $50 \%$ chance to gain a number of years and, thus, live more than 30 years, but also a $50 \%$ chance to lose life years and live less than 30 years in full health. Immediately after taking the drug, the doctor can determine whether the drug strikes or not. Once this is known, one cannot change the situation.

No drug

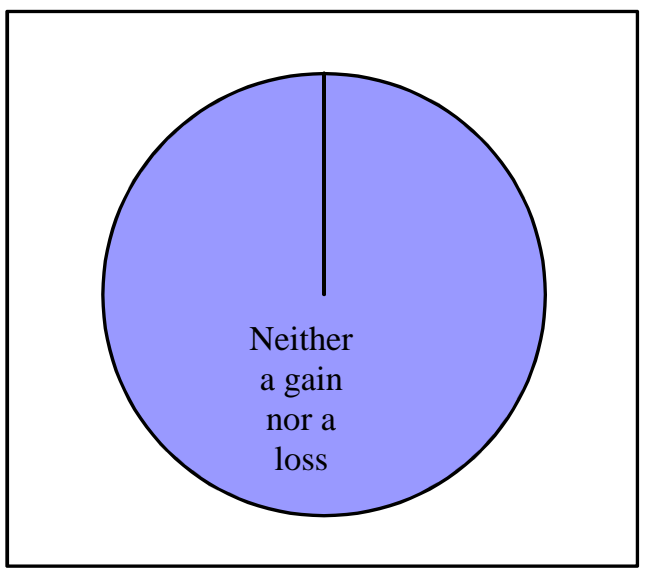

Drug

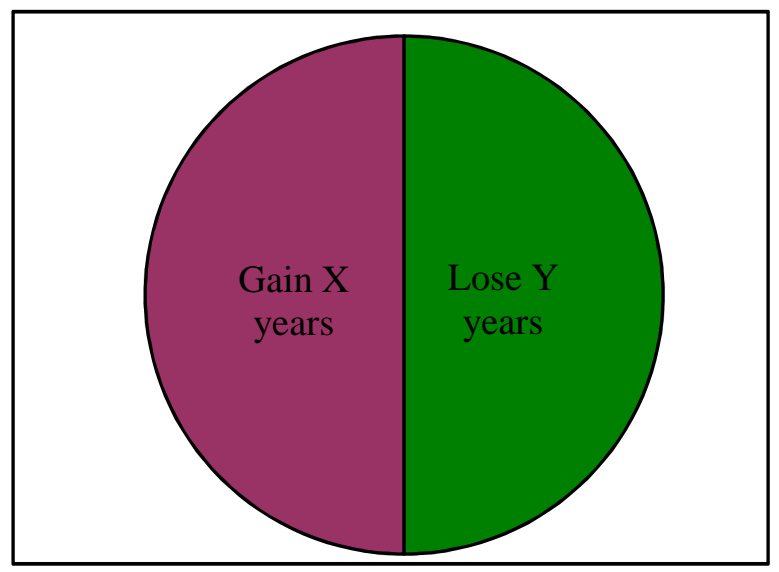




\section{Appendix 2: Individual results}
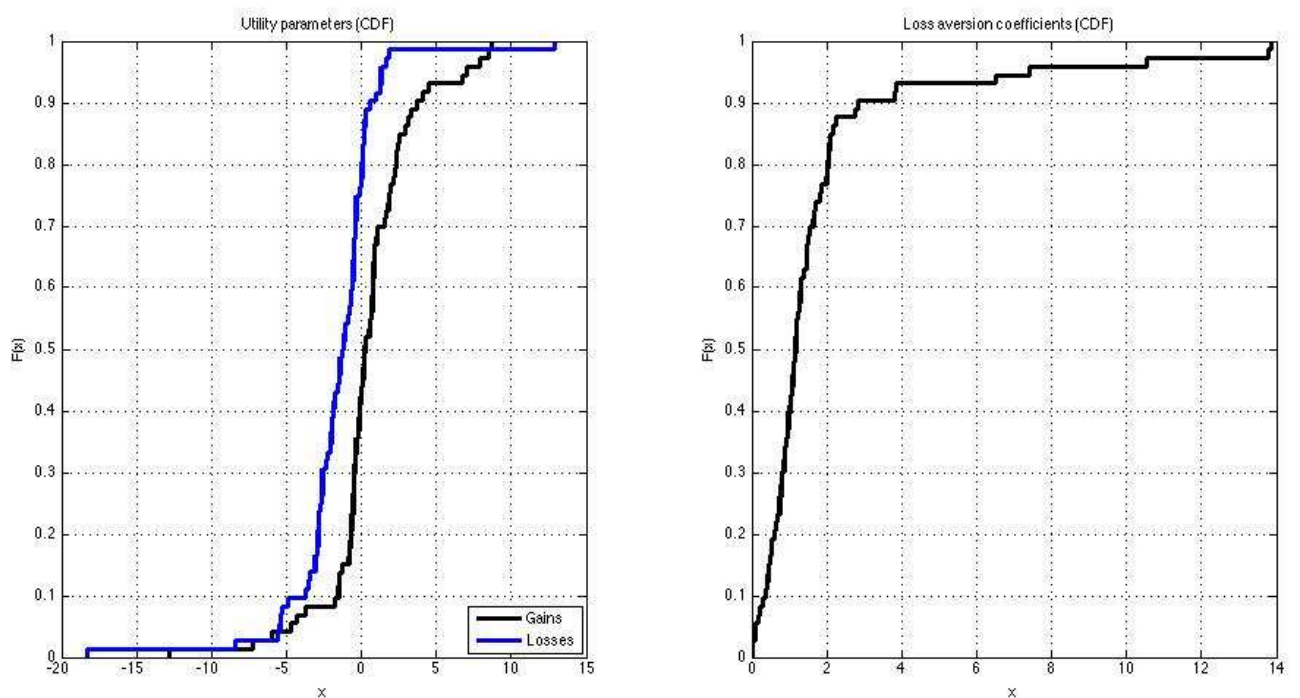

Figure 1: Cumulative distribution functions (CDF) of individual parameters. Left panel: distributions of utility parameters for gains (black line) and losses (blue line). Right panel: distribution of loss aversion indexes. 


\section{References}

-Abdellaoui M. Parameter-Free Elicitation of Utility and Probability Weighting Functions. Management Science 2000;46; 1497-1512.

-Abdellaoui M, Bleichrodt $\mathrm{H}$, l'Haridon O. A tractable method to measure utility and loss aversion under prospect theory. Journal of Risk and Uncertainty 2008;36; 245-266.

-Abdellaoui M, Bleichrodt H, Paraschiv C. Loss Aversion Under Prospect Theory: A Parameter-Free Measurement. Management Science 2007;53; 1659-1674.

-Abdellaoui M, Diecidue E, Öncüler A. Risk Preferences at Different Time Periods: An Experimental Investigation. Management Science 2011a;57; 975-987.

-Abdellaoui M, l'Haridon O, Paraschiv C. Experienced vs. Described Uncertainty: Do We Need Two Prospect Theory Specifications? Management Science 2011b;57; 1879-1895.

-Abellán-Perpinán JM, Bleichrodt H, Pinto-Prades JL. The predictive validity of prospect theory versus expected utility in health utility measurement. Journal of Health Economics 2009b;28; 1039-1047.

-Abellán-Perpinán JM, Pinto JL, Méndez-Martinez I, Badia-Llach X. Towards a better QALY model. Health Economics 2006;15; 665-676.

-Abellán-Perpinán, J.M., Sánchez-Martínez, F.I., Martínez-Pérez, J.E., Méndez-Martínez, I. 2009a. Debiasing EQ-5D tariffs. New estimations of the Spanish EQ-5D value set under nonexpected utility. Economic Working Papers at Centro de Estudios Andaluces E2009/06, Centro de Estudios Andaluces.

-Attema AE. Developments in time preference and their implications for medical decision making. Journal of the Operational Research Society 2012;63; 1388-1399.

-Attema AE, Bleichrodt H, Wakker PP. A direct method for measuring discounting and QALYs more easily and reliably. Medical Decision Making 2012;32; 583-593.

-Attema AE, Brouwer WBF. The correction of TTO-scores for utility curvature using a riskfree utility elicitation method. Journal of Health Economics 2009;28; 234-243.

-Attema AE, Brouwer WBF. The way that you do it? An elaborate test of procedural invariance of TTO, using a choice-based design. The European Journal of Health Economics $2012 ; 13 ; 491-500$.

-Bleichrodt H, Abellan-Perpiñan JM, Pinto-Prades JL, Mendez-Martinez I. Resolving Inconsistencies in Utility Measurement Under Risk: Tests of Generalizations of Expected Utility. Management Science 2007;53; 469-482.

-Bleichrodt H, Johannesson M. Time Preference for Health: A Test of Stationarity versus Decreasing Timing Aversion. Journal of Mathematical Psychology 2001;45; 265-282. 
-Bleichrodt H, Miyamoto J. A Characterization of Quality-Adjusted Life-Years Under Cumulative Prospect Theory. Mathematics of Operations Research 2003;28; 181-193.

-Bleichrodt H, Pinto JL. A Parameter-Free Elicitation of the Probability Weighting Function in Medical Decision Analysis. Management Science 2000;46; 1485-1496.

-Bleichrodt H, Pinto JL. Loss aversion and scale compatibility in two-attribute trade-offs. Journal of Mathematical Psychology 2002;46; 315-337.

-Bleichrodt H, Pinto JL. The validity of QALYs under non-expected utility. The Economic Journal 2005;115; 533-550.

-Bleichrodt H, Pinto JL, Abellán-Perpinán JM. A consistency test of the time trade-off. Journal of Health Economics 2003;22; 1037-1052.

-Bleichrodt H, Pinto JL, Wakker PP. Making Descriptive Use of Prospect Theory to Improve the Prescriptive Use of Expected Utility. Management Science 2001;47; 1498-1514.

-Bleichrodt H, Quiggin J. Characterizing QALYs under a General Rank Dependent Utility Model. Journal of Risk and Uncertainty 1997;15; 151-165.

-Booij AS, van de Kuilen G. A parameter-free analysis of the utility of money for the general population under prospect theory. Journal of Economic Psychology 2009;30; 651-666.

-Booij A, van Praag B, van de Kuilen G. A parametric analysis of prospect theory's functionals for the general population. Theory and Decision 2010;68; 115-148.

-Bostic R, Herrnstein RJ, Luce RD. The effect on the preference-reversal phenomenon of using choice indifferences. Journal of Economic Behavior \& Organization 1990;13; 193-212.

-Chateauneuf A, Cohen M. Risk Seeking with Diminishing Marginal Utility in a Nonexpected Utility Model. Journal of Risk and Uncertainty 1994;9; 77-91.

-Fehr-Duda H, de Gennaro M, Schubert R. Gender, Financial Risk, and Probability Weights. Theory and Decision 2006;60; 283-313.

-Fox CR, Poldrack RA 2008. Prospect theory and the brain. In: Glimcher P, Fehr E, Camerer C, Poldrack RA (Eds), Handbook of Neuroeconomics, San Diego: Academic Press; 2008.

-Frederick S, Loewenstein G, O'Donoghue T. Time discounting and time preference: A critical review. Journal of Economic Literature 2002;40; 351-401.

-Gafni A, Torrance GW. Risk Attitude and Time Preference in Health. Management Science $1984 ; 30 ; 440-451$.

-Gonzalez R, Wu G. On the shape of the probability weighting function. Cognitive Psychology 1999;38; 129-166.

-Kahneman D, Tversky A. Prospect Theory: An Analysis of Decision under Risk. Econometrica 1979;47; 263-291. 
-Knoph Kvamme M, Gyrd-Hansen D, Olsen JA, Kristiansen IS. Increasing marginal utility of small increases in life-expectancy? Results from a population survey. Journal of Health Economics 2010;29; 541-548.

-Köbberling V, Wakker PP. An index of loss aversion. Journal of Economic Theory $2005 ; 122 ; 119-131$.

-Laughhunn DJ, Payne JW, Crum R. Managerial Risk Preferences for Below-Target Returns. Management Science 1980;26; 1238-1249.

-Libby R, Fishburn PC. Behavioral Models of Risk Taking in Business Decisions: A Survey and Evaluation. Journal of Accounting Research 1977;15; pp. 272-292.

-Llewellyn-Thomas H, Sutherland HJ, Tibshirani R, Ciampi A, Till JE, Boyd NF. The measurement of patients' values in medicine. Medical Decision Making 1982;2; 449-462.

-Marquis MS, Holmer MR. Alternative Models of Choice Under Uncertainty and Demand for Health Insurance. The Review of Economics and Statistics 1996;78; pp. 421-427.

-Miyamoto JM, Eraker SA. Parametric models of the utility of survival duration: Tests of axioms in a generic utility framework. Organizational Behavior and Human Decision Processes 1989;44; 166-202.

-Ogaki M, Zhang Q. Decreasing Relative Risk Aversion and Tests of Risk Sharing. Econometrica 2001;69; pp. 515-526.

-Oliver A. The internal consistency of the standard gamble: tests after adjusting for prospect theory. Journal of Health Economics 2003;22; 659-674.

-Pinto-Prades JL, Loomes G, Brey R. Trying to estimate a monetary value for the QALY. Journal of Health Economics 2009;28; 553-562.

-Pliskin JS, Shepard D, Weinstein MC. Utility functions for life years and health status. Operations Research 1980;28; 206-224.

-Quiggin J. A theory of anticipated utility. Journal of Economic Behavior and Organization $1982 ; 3 ; 323-343$.

-Robinson A, Loomes G, Jones-Lee M. Visual Analog Scales, Standard Gambles, and Relative Risk Aversion. Medical Decision Making 2001;21; 17-27.

-Schmidt U, Traub S. An Experimental Test of Loss Aversion. Journal of Risk and Uncertainty 2002;25; 233-249.

-Schmidt U, Zank H. A Genuine Foundation for Prospect Theory. Journal of Risk and Uncertainty 2012;45; 97-113.

-Starmer C. Developments in non-expected utility theory: The hunt for a descriptive theory of choice under risk. Journal of Economic Literature 2000;38; 332-382. 
-Stiggelbout AM, Kiebert GM, Kievit J, Leer JW, Stoter G, de Haes JC. Utility assessment in cancer patients: adjustment of time tradeoff scores for the utility of life years and comparison with standard gamble scores. Medical Decision Making 1994;14; 82-90.

-Stott H. Cumulative prospect theory's functional menagerie. Journal of Risk and Uncertainty 2006;32; 101-130.

-Treadwell JR, Lenert LA. Health Values and Prospect Theory. Medical Decision Making $1999 ; 19 ; 344-352$.

-Tversky A, Kahneman D. Rational choice and the framing of decisions. Journal of Business 1986;59; S251-S278.

-Tversky A, Kahneman D. Loss aversion in riskless choice: A reference-dependent model. Quarterly Journal of Economics 1991;106; 1039-1061.

-Tversky A, Kahneman D. Advances in Prospect Theory: Cumulative Representation of Uncertainty. Journal of Risk and Uncertainty 1992;5; 297-323.

-van de Kuilen G, Wakker PP. The Midweight Method to Measure Attitudes Toward Risk and Ambiguity. Management Science 2011;57; 582-598.

-van Nooten FE, Brouwer WBF. The influence of subjective expectations about length and quality of life on time trade-off answers. Health Economics 2004;13; 819-823.

-van Osch SMC, Stiggelbout AM. The construction of standard gamble utilities. Health Economics 2008; 17; 31-40.

-van Osch SMC, van den Hout WB, Stiggelbout AM. Exploring the Reference Point in Prospect Theory: Gambles for Length of Life. Medical Decision Making 2006;26; 338-346.

-van Osch SM, Wakker PP, van den Hout, W. B., Stiggelbout AM. Correcting biases in standard gamble and time tradeoff utilities. Medical Decision Making 2004;24; 511-517.

-Verhoef LCG, de Haan AFJ, van Daal WA. Risk attitude in gambles with years of life: Empirical support for prospect theory Medical Decision Making 1994;14; 194-200.

-Wakker PP. Prospect theory: For risk and ambiguity, Cambridge: Cambridge University Press; 2010.

-Wakker P. Separating marginal utility and probabilistic risk aversion. Theory and Decision 1994;36; 1-44.

-Wakker P, Deneffe D. Eliciting von Neumann-Morgenstern Utilities When Probabilities Are Distorted or Unknown. Management Science 1996;42; 1131-1150.

-Wakker P, Stiggelbout A. Explaining Distortions in Utility Elicitation through the Rankdependent Model for Risky Choices. Medical Decision Making 1995;15; 180-186. 
-Wu G, Gonzalez R. Nonlinear Decision Weights in Choice Under Uncertainty. Management Science 1999;45; 74-85. 